\title{
Oxidized BAL fluid proteins in patients with interstitial lung diseases
}

\author{
A-G. Lenz*, U. Costabel**, K.L. Maier*
}

Oxidized BAL fluid proteins in patients with interstitial lung diseases. A-G. Lenz, U. Costabel, K.L. Maier. (C)ERS Journals Ltd 1996.

ABSTRACT: Oxygen-derived free radicals, released by phagocytic cells, have been postulated to contribute to lung tissue damage. We therefore investigated oxidative damage to proteins from bronchoalveolar lavage fluid (BALF) as an indicator of oxidative stress and to assess antioxidant defences in the lungs.

We examined BAL fluids from patients with interstitial lung diseases, such as idiopathic pulmonary fibrosis (IPF, nonsmokers (NS) and smokers (S)), sarcoidosis (SARC, nonsmokers), and asbestosis (ASB, ex-smokers (EXS)). The oxidation of BALF proteins is accompanied by the introduction of carbonyl groups into their amino acid side-chains and can be quantitated by labelling these groups with tritiated borohydride.

The total lung content of oxidized proteins recovered by bronchoalveolar lavage (BAL) was $0.3 \pm 0.07 \mathrm{nmol}$ carbonyl $\cdot \mathrm{mL}^{-1}$ BALF (mean \pm SEM) in the NS control group $(n=9)$ and tended to be increased, in the asymptomatic $S$ group $(n=8 ; 0.59 \pm 0.14$ $\left.\mathrm{nmol} \cdot \mathrm{mL}^{-1}\right)$. This parameter was significantly elevated both in IPF-NS $(n=14 ; 0.84 \pm$ $0.2 \mathrm{nmol}$ carbonyl $\cdot \mathrm{mL}^{-1}$ BALF) and SARC-NS $\left(\mathrm{n}=15 ; 0.73 \pm 0.16 \mathrm{nmol} \cdot \mathrm{mL}^{-1}\right)$ as compared with the NS control. On the contrary, in smoking patients with IPF $\left(\mathrm{n}=6 ; 0.41 \pm 0.1 \mathrm{nmol}\right.$ carbonyl $\left.\cdot \mathrm{mL}^{-1} \mathrm{BALF}\right)$ and also in ASB-EXS $(\mathrm{n}=6 ; 0.37 \pm 0.06$ nmol.mL $\mathrm{L}^{-1}$ ) it was not different from NS controls. The total amount of oxidized proteins correlated positively with the absolute number of eosinophils (EOS) in IPFNS, IPF-S and SARC, and also with absolute polymorphonuclear neutrophil (PMN) numbers in IPF-NS and IPF-S.

In conclusion, oxidative damage of BALF proteins occurred in nonsmoking patients with IPF and SARC. The amount of oxidized bronchoalveolar lavage fluid protein may provide a quantitative assessment of oxygen burden, a balance between oxidant stress and antioxidant defences.

Eur Respir J., 1996, 9, 307-312.
*GSF-Forschungszentrum für Umwelt und Gesundheit, Institut für Inhalationsbiologie, Oberschleissheim, FRG.**Abteilung Pneumologie/Allergologie, Ruhrlandklinik, Essen, FRG.

Correspondence: A-G. Lenz

GSF-Forschungszentrum für Umwelt und Gesundheit, Institut für Inhalationsbiologie Ingolstädter Landstrasse 1 D-85764 Oberschleissheim FRG

Keywords: Bronchoalveolar lavage carbonyl assay

interstitial lung disease

oxidative stress

protein oxidation

smoking

Received: December 201994

Accepted after revision October 71995
Oxidative mechanisms are currently discussed as playing a crucial role in the genesis of inflammatory lung diseases [1-3]. Reactive oxygen metabolites, such as superoxide anions $\left(\mathrm{O}_{2}^{-}\right)$, hydroxyl radicals or $\mathrm{H}_{2} \mathrm{O}_{2}$, are released from resident alveolar macrophages (AMs) and, during inflammation, also from invading polymorphonuclear neutrophils (PMNs) and eosinophils (EOSs) in exaggerated amounts. Apart from their beneficial microbial killing effect, oxidants may deleteriously affect lung tissue by oxidative modification of structural and functional proteins [4-6]. Oxidizing air pollutants, such as ozone or cigarette smoke, might damage bronchoalveolar lavage fluid (BALF) proteins directly by oxidation [3, 7-9], or by triggering an inflammatory response. In patients with idiopathic pulmonary fibrosis (IPF), AMs and PMNs dominate the inflammatory cell population in the lower respiratory tract, releasing ex-vivo more oxidants both spontaneously and after stimulation than do cells from healthy nonsmoking individuals [10]. Similar results are obtained with BALF cells from smokers [11] or patients with sarcoidosis (SARC) [12]. To protect the lung from unwanted oxidation, lung tissue and the epithelial lining fluid (ELF) contain various antioxidants [13-15]. As recently reported, glutathione (GSH), one of the major antioxidants in ELF, is markedly decreased in IPF [16], whereas it is increased in smokers [17]. In contrast, vitamin $\mathrm{E}$, another potent scavenger of oxygen radicals, is shown to be reduced in smokers [18]. It is evident that the balance between antioxidants and oxidants in the lungs is very important and that any disturbance of this balance may favour pathophysiological events, leading to acute or chronic damage and dysfunction.

Phagocytic cells, such as activated AMs, mediate metalcatalysed oxidation systems that oxidize amino acid residues in proteins $[4,5,19,20]$. Metal-catalysed oxidation of proteins is characterized by the introduction of carbonyl groups into side-chains of amino acids, and can be quantitated by labelling these groups with tritiated borohydride $[21,22]$. The current proposed mechanism for this kind of site-directed protein oxidation (Fenton 
reaction) involves the binding of free transition metal ions, such as $\mathrm{Fe}(\mathrm{II})$ or $\mathrm{Cu}(\mathrm{I})$, to metal-binding sites in proteins, followed by interaction with $\mathrm{H}_{2} \mathrm{O}_{2}$ to generate hydroxyl radicals or ferryl ions [23]. These highly reactive oxygen species then attack amino acid residues, adjacent to the metal-binding site $[4,19,20]$, to form carbonyl groups. $\mathrm{H}_{2} \mathrm{O}_{2}$ may originate from activated phagocytes, and transition metal ions may be either released endogenously during inflammatory reactions [24], or inhaled from polluted air or cigarette smoke [25]. We and others have demonstrated that oxidatively modified proteins, as measured by their carbonyl content, accumulate in BALF of monkeys after exposure to a hyperbaric atmosphere [26], in pulmonary fluid of ventilated neonates [27], in rat hepatocytes during ageing and exposure to hyperoxia [20], in normal human erythrocytes and dermal fibroblasts as a function of donor age [19], and in activated neutrophils [4].

To investigate whether an oxidant burden of the lungs is reflected in an oxidative damage to BALF proteins due to metal-catalysed oxidation, we measured proteinbound carbonyl in human BALF from asymptomatic smokers and patients with IPF (nonsmokers (NS) and smokers (S)), SARC (nonsmokers), and asbestosis (exsmokers (EXS)) and compared them with nonsmoking individuals. Results of this study revealed that the protein carbonyl content may be an indicator for oxidative reactions occurring in the respiratory tract.

\section{Methods}

\section{Study population}

Nonsmoking control group and asymptomatic smoking group. The nonsmoker group consisted of nine healthy nonsmoking volunteers (4 males, 5 females; mean age $25 \mathrm{yrs}$, range 23-32 yrs). The smoker group consisted of eight healthy smoking volunteers (5 males, 3 females; mean age 31 yrs, range 25-37 yrs) with a mean smoking history of $9.4 \pm 1.3$ pack-yrs. All volunteers were free of respiratory symptoms and had normal chest radiographs and pulmonary function tests.

Patients with idiopathic pulmonary fibrosis. In this group, 14 patients were nonsmokers ( 6 males and 8 females; mean age $61 \mathrm{yrs}$, range $42-75 \mathrm{yrs}$ ), and six were smokers (4 males and 2 females; mean age 45 yrs, range 28-61 yrs) with a mean smoking history of $31 \pm 10$ pack-yrs. The diagnosis was based on a compatible clinical picture, chest radiograph, pulmonary function tests, and a confirmatory open lung biopsy. In the nonsmoker group, 12 patients were treated with prednisone $\left(17 \pm 2 \mathrm{mg} \cdot \mathrm{day}^{-1}\right)$, and two additionally received cyclophosphamide (100 $\left.\mathrm{mg} \cdot \mathrm{day}^{-1}\right)$ or azathioprine $\left(100 \mathrm{mg} \cdot \mathrm{day}^{-1}\right)$. In the smoker group, two patients were treated with prednisone (30 and $\left.60 \mathrm{mg} \cdot \mathrm{day}^{-1}\right)$, and one received prednisone $\left(20 \mathrm{mg} \cdot \mathrm{day}^{-1}\right)$ plus cyclophosphamide $\left(125 \mathrm{mg} \cdot \mathrm{day}^{-1}\right)$. None of the patients was on continuous oxygen therapy.
Patients with sarcoidosis. All 15 patients were nonsmokers ( 7 males and 8 females; mean age 46 yrs, range 22-77 yrs). The diagnosis was based on compatible clinical findings: biopsy evidence of epithelioid cell granulomas; no evidence of mycobacterial, fungal or parasitic infection; and no history of exposure to organic or inorganic dusts. By chest radiography, four were stage I, 10 were stage II, and one was stage III. In this group, five patients received prednisone $\left(5-10 \mathrm{mg} \cdot \mathrm{day}^{-1}\right)$.

Patients with asbestosis. The six patients with asbestosis had quit smoking (ex-smokers) (6 males; mean age 56 yrs, range 51-60 yrs).

\section{Chemicals}

Sodium borohydride was purchased from Amersham Buchler (Braunschweig, FRG); Dowex 50 from Biorad (München, FRG); and all other chemicals (analytical grade) from Merck (Darmstadt, FRG).

\section{Collection of bronchoalveolar lavage (BAL) cells and $B A L F$}

After obtaining informed consent from each patient and healthy volunteer, BAL was performed by standardized washing of the right middle lobe of the lung with $5 \times 20 \mathrm{~mL}$ of sterile $0.9 \%(\mathrm{w} / \mathrm{v})$ saline during fibreoptic bronchoscopy. The fluid recovered was filtered through gauze to remove mucus and centrifuged at 500x $\mathrm{g}$ for $10 \mathrm{~min}$. From the cell pellets, the total and differential cell counts were determined as described previously [28]. The supernatants, containing the BALF proteins, were dialysed for $3 \mathrm{~h}$ at $4{ }^{\circ} \mathrm{C}$ against water and aliquots were freeze dried to provide about $100 \mu \mathrm{g}$ protein per tube [21].

\section{Determination of protein carbonyl content}

The level of protein carbonyl groups was measured in the dried samples of BALF supernatant by reduction of the carbonyl group to an alcohol with tritiated sodium borohydride. To remove any label not present in amino acids, the proteins were hydrolysed and the amino acids were separated by chromatography on Dowex 50 [21, 22].

\section{Determination of protein from the acid hydrolysates}

Total amino acid content was measured in an aliquot of the hydrolysed samples using o-phthalaldehyde as described previously [21, 22]. An average molecular mass of $50 \mathrm{kDa}$ for proteins and $110 \mathrm{Da}$ for amino acid residues was assumed in order to convert the amino acid determination into an estimate of total protein. The carbonyl content can then be expressed as nmol carbonyl. $\mathrm{mL}^{-1}$ BALF or as nmol carbonyl. $\mathrm{mg}^{-1}$ protein. 


\section{Statistical analysis}

Statistical analysis was performed using the software packages Statistical Analysis System (SAS) version 6.08. Results were expressed as the arithmetic mean \pm SEM. To indicate differences between the various groups the data were submitted to the nonparametric Kruskal-Wallis oneway analysis of variance (ANOVA) procedure by ranks. Post hoc comparison of groups with the NS control group (many-one comparison) was made by using the Wilcoxon rank-sum test. Differences with $\mathrm{p}$ less than 0.05 were considered significant. Pearson correlation coefficients were calculated by linear regression analysis.

\section{Results}

\section{BAL cellular constituents}

Fluid recovery was the same in all groups, with the exception of the asbestosis (ASB) group in which it was significantly reduced compared to the control group (table 1). The total number of BAL cells obtained from the smoker (S) group was 5.5 fold increased compared to the nonsmoker (NS) group (table 1) largely due to the increase in AM counts. Total PMN and EOS counts were also significantly increased in the $\mathrm{S}$ group, but relative numbers were still low (2.5 and $0.4 \%$ of total BAL cells, respectively). Lymphocyte counts were not different from the NS control. IPF-NS was characterized by a moderate increase (twofold) in total cell counts, which was caused by a significant increase of PMNs (16\% of total BAL cells) and EOSs (5\% of total BAL cells) counts. IPF-S showed similar increases in AM counts to the smoking control group, but higher increases in PMNs (8\% of total BAL cells) and EOSs (4\% of total BAL cells). In SARCNS the total number of cells was increased twofold, mainly due to an increase in lymphocytes $(36 \%$ of total
BAL cells). In ASB-EXS the total number of cells was increased moderately due to increases in AMs, PMNs and EOSs but none of the increases was significant as compared with the NS group.

\section{BAL protein content and protein carbonyl content}

Total protein content in BALF of the control group was $62 \mu \mathrm{g} \cdot \mathrm{mL}^{-1}$. This parameter was statistically the same in S, IPF (NS and S), and ASB-EXS compared with the NS control (table 2). In SARC-NS protein values were 2.7 fold increased.

As shown in figure 1, the total lung content of oxidized proteins recovered by BAL (nmol carbonyl $\cdot \mathrm{mL}^{-1}$ BALF) varied distinctly more in the S, IPF-NS, IPF-S, SARC-NS and ASB-EXS groups than in the NS control group, with larger boxes and longer "whiskers". Analysis of the data by the Kruskal-Wallis procedure revealed significant differences between the six groups whether expressed as nmol carbonyl. $\mathrm{mL}^{-1}$ BALF ( $\left.\mathrm{p}=0.042\right)$, as nmol carbonyl $\cdot \mathrm{mg}^{-1}$ protein $(\mathrm{p}=0.032)$, or as $\mathrm{nmol}$ carbonyl $\cdot \mathrm{mL}^{-1}$ BALF $\cdot 10^{-6}$ phagocytes $(\mathrm{p}=0.008)$. The Wilcoxon ranksum test for comparison of groups with the NS control indicated significant increases of nmol carbonyl $\cdot \mathrm{mL}^{-1}$ BALF in the IPF-NS $(\mathrm{p}=0.004)$ and SARC-NS $(\mathrm{p}=0.027)$ groups, but not in the $S(p=0.075)$, IPF-S $(p=0.51)$, and ASB-EXS (p=0.22) groups (fig. 1 and table 2). However, the data in the $\mathrm{S}$ group suggested a tendency to increased values. When carbonyl values were related to the protein content (nmol carbonyl $\cdot \mathrm{mg}^{-1}$ protein) only the IPF-NS group showed a significant increase $(\mathrm{p}=0.0067)$, and the $\mathrm{S}$ group showed a tendency to increased values $(\mathrm{p}=0.059)$ as compared with the NS control (table 2).

The effectiveness of phagocytic cells (AM+PMN+EOS) in generating carbonyl groups was estimated by relating the amount of carbonyl groups to a standard number of phagocytes (nmol carbonyl $\cdot \mathrm{mL}^{-1} \mathrm{BALF} \cdot 10^{-6}$ phagocytes). The carbonyl values on a per cell basis were distinctly

Table 1. - Total and differential cell counts in BAL from normal nonsmokers (NS), asymptomatic smokers (S), and patients with idiopathic pulmonary fibrosis (IPF), sarcoidosis (SARC) or asbestosis (ASB)

\begin{tabular}{|c|c|c|c|c|c|c|}
\hline BALF cells & $\begin{array}{l}\text { NS } \\
(n=9)\end{array}$ & $\underset{(n=8)}{S}$ & $\begin{array}{c}\text { IPF-NS } \\
(n=14)\end{array}$ & $\begin{array}{l}\text { IPF-S } \\
(n=6)\end{array}$ & $\begin{array}{l}\text { SARC-NS } \\
(n=15)\end{array}$ & $\begin{array}{c}\text { ASB-EXS } \\
(\mathrm{n}=6)\end{array}$ \\
\hline Fluid recovery \% & $64 \pm 3.5$ & $56 \pm 4.1$ & $59 \pm 3.6$ & $59 \pm 3.3$ & $64 \pm 3$ & $47 \pm 6.8^{*}$ \\
\hline \multicolumn{7}{|l|}{ Total cell count } \\
\hline$\times 10^{4} \cdot \mathrm{mL}^{-1}$ & $7.7 \pm 2.7$ & $42 \pm 9.8 * *$ & $15 \pm 2.4 *$ & $42 \pm 11 *$ & $16 \pm 3 *$ & $24 \pm 8.7$ \\
\hline \multicolumn{7}{|l|}{ Macrophage count } \\
\hline$\%$ & $90 \pm 2.8$ & $93 \pm 0.8$ & $59 \pm 5.3 * * *$ & $87 \pm 7.6$ & $63 \pm 6^{* *}$ & $90 \pm 2.2$ \\
\hline$\times 10^{4} \cdot \mathrm{mL}^{-1}$ & $6.5 \pm 2.0$ & $39 \pm 9.2 * *$ & $8.9 \pm 1.6$ & $37 \pm 11.6^{* *}$ & $9.8 \pm 2.1$ & $22 \pm 8.1$ \\
\hline \multicolumn{7}{|l|}{ Neutrophil count } \\
\hline$\%$ & $1.1 \pm 0.3$ & $2.5 \pm 0.7$ & $16 \pm 2.0 * * *$ & $8.4 \pm 3.8^{*}$ & $1.1 \pm 0.2$ & $1.5 \pm 0.6$ \\
\hline$\times 10^{4} \cdot \mathrm{mL}^{-1}$ & $0.07 \pm 0.03$ & $1.1 \pm 0.3^{*}$ & $2.2 \pm 0.4 * * *$ & $4.7 \pm 2.8 * *$ & $0.1 \pm 0.03$ & $0.4 \pm 0.2$ \\
\hline \multicolumn{7}{|l|}{ Eosinophil count } \\
\hline$\%$ & $0.2 \pm 0.05$ & $0.4 \pm 0.1$ & $5.1 \pm 1.3 * * *$ & $4.0 \pm 1.8 * *$ & $0.4 \pm 0.1$ & $9 \pm 0.3^{*}$ \\
\hline$\times 10^{4} \cdot \mathrm{mL}^{-1}$ & $0.02 \pm 0.01$ & $0.1 \pm 0.03 * * *$ & $0.7 \pm 0.2 * * *$ & $2.1 \pm 1.3^{* *}$ & $0.06 \pm 0.02 *$ & $0.2 \pm 0.1$ \\
\hline \multicolumn{7}{|l|}{ Lymphocyte count } \\
\hline$\%$ & $7.6 \pm 2.1$ & $3.1 \pm 0.06$ & $20 \pm 4.3$ & $5.1 \pm 3.0$ & $36 \pm 5.9 * *$ & $6.7 \pm 1.8$ \\
\hline$\times 10^{4} \cdot \mathrm{mL}^{-1}$ & $0.9 \pm 0.6$ & $1.1 \pm 0.41$ & $3.3 \pm 1.1 *$ & $1.4 \pm 0.6$ & $5.6 \pm 1.8 * *$ & $1.3 \pm 0.4$ \\
\hline
\end{tabular}

Values are presented as mean \pm SEM. *: $\mathrm{p}<0.05 ; * *: \mathrm{p}<0.005 ; * * *: \mathrm{p}<0.0005$, p-values for comparison with NS group. BALF: bronchoalveolar lavage fluid; EXS: ex-smokers. 
Table 2. - Total protein carbonyl content in BALF from normal nonsmokers (NS), asymptomatic smokers (S), and patients with idiopathic pulmonary fibrosis (IPF), sarcoidosis (SARC) or asbestosis (ASB)

\begin{tabular}{|c|c|c|c|c|c|c|}
\hline BALF parameters & $\begin{array}{l}\text { NS } \\
(\mathrm{n}=9)\end{array}$ & $\underset{(n=8)}{S}$ & $\begin{array}{c}\text { IPF-NS } \\
(\mathrm{n}=14)\end{array}$ & $\begin{array}{l}\text { IPF-S } \\
(n=6)\end{array}$ & $\begin{array}{c}\text { SARC-NS } \\
(\mathrm{n}=15)\end{array}$ & $\begin{array}{c}\text { ASB-EXS } \\
\quad(n=6)\end{array}$ \\
\hline $\begin{array}{l}\text { Protein } \\
\qquad \mu \mathrm{g} \cdot \mathrm{mL}^{-1}\end{array}$ & $62 \pm 14$ & $72 \pm 13$ & $100 \pm 22$ & $90 \pm 43$ & $166 \pm 56^{*}$ & $68 \pm 8$ \\
\hline $\begin{array}{l}\text { Carbonyl } \\
\mathrm{nmol} \cdot \mathrm{mL}^{-1} \\
\mathrm{nmol} \cdot \mathrm{mg}^{-1}\end{array}$ & $\begin{array}{l}0.3 \pm 0.07 \\
5.3 \pm 0.6\end{array}$ & $\begin{array}{c}0.59 \pm 0.14 \\
8.3 \pm 1.5\end{array}$ & $\begin{array}{c}0.84 \pm 0.21^{* *} \\
8.3 \pm 0.7^{*}\end{array}$ & $\begin{array}{c}0.41 \pm 0.11 \\
5.9 \pm 0.9\end{array}$ & $\begin{array}{c}0.73 \pm 0.16^{*} \\
5.7 \pm 0.6\end{array}$ & $\begin{array}{c}0.37 \pm 0.06 \\
5.7 \pm 0.3\end{array}$ \\
\hline $\begin{array}{c}\text { Carbonyl per phagocyte } \\
\mathrm{nmol} \cdot \mathrm{mL}^{-1} \cdot 10^{-6} \text { cells } \\
\mathrm{nmol} \cdot \mathrm{mg}^{-1} \cdot 10^{-6} \text { cells }\end{array}$ & $\begin{array}{c}7.4 \pm 1.8 \\
135 \pm 39\end{array}$ & $\begin{array}{c}2.9 \pm 1.1^{*} \\
39 \pm 13^{*}\end{array}$ & $\begin{array}{c}8.6 \pm 1.7 \\
94 \pm 16\end{array}$ & $\begin{array}{l}1.1 \pm 0.2 * * \\
22 \pm 6 * *\end{array}$ & $\begin{array}{c}9.6 \pm 2 \\
102 \pm 29\end{array}$ & $\begin{array}{c}5.1 \pm 2.6 \\
126 \pm 96\end{array}$ \\
\hline
\end{tabular}

Values are presented as mean \pm SEM. *: $\mathrm{p}<0.05 ; * *$ : $\mathrm{p}<0.005$, p-values for comparison with NS group. \$: phagocytes (AM+PMN+EOS). For abbreviations see legend to table 1 .

reduced in both smoking groups using the Wilcoxon test ( $\mathrm{S}$ group, $\mathrm{p}=0.04$; and IPF-S group, $\mathrm{p}=0.004$ ), whereas in IPF-NS, in SARC-NS and in ASB-EXS values were not different from the NS control (table 2).

Correlation between protein carbonyl content and cellular constituents

Total carbonyl in BALF (nmol carbonyl $\cdot \mathrm{mL}^{-1} \mathrm{BALF}$ ) of the IPF-NS, IPF-S and SARC-NS but not the $\mathrm{S}$ group correlated significantly with absolute EOS numbers $(\mathrm{r}=0.61$, $\mathrm{p}=0.02, \mathrm{n}=14 ; \mathrm{r}=0.92, \mathrm{p}=0.009, \mathrm{n}=6$; and $\mathrm{r}=0.68, \mathrm{p}=0.005$, $\mathrm{n}=15$, respectively). In IPF-NS and IPF-S, carbonyl also

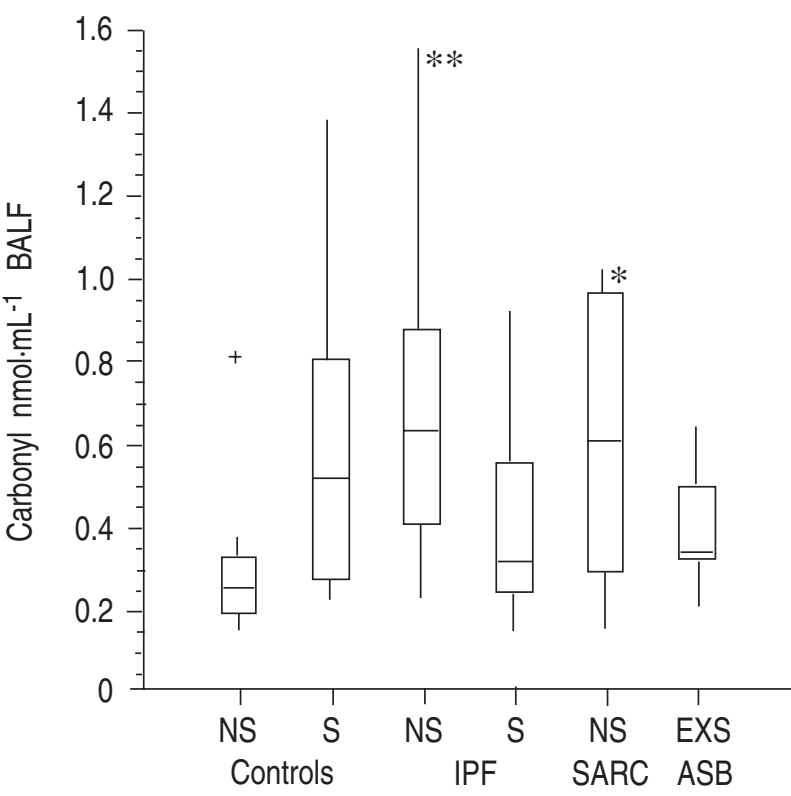

Fig. 1. - Box plot of the carbonyl content in BALF protein from healthy nonsmokers (NS), asymptomatic smokers (S), patients with idiopathic pulmonary fibrosis (IPF-NS and IPF-S), sarcoidosis (SARCNS), and asbestosis (ASB-EXS). The box covers the middle $50 \%$ of the data values, between the lower and upper quartile. The "whiskers" extend out to the extremes (minimum and maximum values) that are within 1.5 times the interquartile range, whilst the central line is at median. Unusual values occurring far away from the bulk of the data appear as separate points (+), those beyond the scale are one in IPFNS of 3.23, and two in SARC of 1.97 and $2.28 \mathrm{nmol}$ carbonyl. $\mathrm{mL}^{-1}$ BALF. BALF: bronchoalveolar lavage fluid; EXS: ex-smokers. *: $\mathrm{p}<0.05$; **: $\mathrm{p}<0.005$, for comparison with the NS control. correlated significantly with absolute PMN numbers ( $\mathrm{r}=0.66, \mathrm{p}=0.01$; and $\mathrm{r}=0.92, \mathrm{p}=0.007$, respectively). In SARC-NS there was only a moderate relationship between carbonyl and PMN numbers $(r=0.47, p=0.08)$. No correlation was found with the prevailing cells in BALF, the AMs. In SARC-NS, carbonyl levels also correlated with lymphocyte counts $(\mathrm{r}=0.54, \mathrm{p}=0.04)$. Ageing, considered as a possible cause for appearance of oxidized proteins $[19,20,29]$, seems not to influence the level of carbonyl in BALF of these controls and patients, at least in the age range examined here (NS, 23-32 yrs; S, 25-37 yrs; IPF-NS, 42-75 yrs; IPF-S, 28-61 yrs; SARC-NS, 22-77 yrs; ASB-EXS, 51-60 yrs). No correlation was found between protein carbonyl content and age in all groups taken together or analysed separately.

\section{Discussion}

This study has shown that proteins in the ELF are targets of the oxidants produced in the lungs. Oxidation of structural and functional proteins usually renders them dysfunctional [5]. Consequently, relevant systems and functions in the respiratory tract, such as the proteaseanti-protease balance, surfactant, or mucus may also become dysfunctional. We had found that oxidatively damaged proteins accumulated in nonsmoking patients with IPF or SARC, but not in smoking patients with IPF or in patients with ASB who had quit smoking. We thus speculated that analysis of formation of carbonyl groups in lung-associated proteins might provide an assessment to specific mechanisms of oxidative injury that are possibly related to structural and functional damage in interstitial lung diseases.

Oxidized protein as an indicator of the oxidative status of the lung can be quantitated as carbonyl $\cdot \mathrm{mL}^{-1} \mathrm{BALF}$, carbonyl. $\mathrm{mg}^{-1}$ protein, or carbonyl per a given number of phagocytes. Using the BALF volume, obtained by repeated washings, as a denominator was considered to be an appropriate method for calculating and comparing our data. However, this normalization is only possible when the recovery of BALF is highly reproducible and not influenced by pathophysiological changes of the lungs. Using BALF protein as denominator, the oxidative burden can be obscured by substantial transudation of plasma proteins 
with a differential susceptibility to metal-catalysed oxidation, such as albumin, transferrin or immunoglobulins. Such mechanism seems to play a role in the SARC-NS group in which BALF volume was a better denominator than BALF protein, because a major protein fraction in the ELF consists of immunoglobulins [30] that are less susceptible to oxidation. In some cases, the calculation of carbonyl-phagocyte ${ }^{-1}$ seems to be reasonable, because this unit indicates the effectiveness of a given number of phagocytes in generating carbonyl groups. Taken together, all three measures are complementary and may be useful in describing the oxidant status of the lung.

Our finding that oxidatively modified proteins (nmol carbonyl $\cdot \mathrm{mL}^{-1} \mathrm{BALF}$ ) are significantly accumulated in the IPF-NS and SARC-NS groups, is consistent with the reported evidence for an activation of the respiratory burst of AMs in these groups [10, 12]. In contrast to these results, we found no changes in this parameter in the IPF$\mathrm{S}$ and ASB-EXS groups.

Multiple possibilities may account for the different levels of oxidatively damaged proteins in the groups. Firstly, the level of oxidatively modified proteins is determined by their turnover, the rates of generation and degradation. It is known that oxidation renders proteins highly susceptible to proteolytic degradation $[6,20,31$, 32]. Secondly, the introduction of carbonyl groups into proteins is dependent on the oxidant stress and the antioxidant capacity in the ELF. Several antioxidant systems are available [13-15] to protect the lung from increased endogenous or exogenous oxidant burden. GSH, a scavenger of oxygen radicals, $\mathrm{H}_{2} \mathrm{O}_{2}$, and myeloperoxidase (MPO)-derived oxidants, may control the oxidation of BALF proteins. Whilst in IPF-NS patients GSH levels in ELF are drastically reduced [16], they are twofold increased in smokers [17]. The deficiency in GSH might, therefore, enhance formation of carbonyl groups in proteins of IPF-NS, whereas the elevated GSH levels might explain why carbonyl levels were not increased to a higher extent in smokers. Thirdly, the availability of catalytic transition metal ions seems to be another important regulative mechanism in the generation of carbonyl groups in proteins. Smokers are known to have an increased iron burden [25], and in regions of tissue inflammation disrupted cells may release iron bound to ferritin or from the transition pool [14, 24]. Finally, smoking habits and inflammatory processes will, certainly, also influence the oxidant-antioxidant balance.

The effectiveness of phagocytic cells $(\mathrm{AM}+\mathrm{PMN}+\mathrm{EOS})$ to contribute to carbonyl formation may also be important in the evaluation of pulmonary oxygen toxicity. This can be assessed by comparison of the protein carbonyl content in BALF with phagocyte levels (nmol carbonyl $\cdot \mathrm{mL}^{-1} \mathrm{BALF} \cdot 10^{-6}$ phagocytes). It would have the implicit assumption, that cells other than AMs, PMNs or EOSs do not contribute markedly to oxidation of extracellular proteins in the ELF, and that substrate is not limiting. The number of phagocytes increased drastically (six fold) in the BALF both of the S and IPF-S group. However, this increase of oxidant producing cells in the two smoking groups was not reflected in a similar increase either in carbonyl-mL $\mathrm{mL}^{-1}$ BALF or carbonyl-phagocyte ${ }^{-1}$.
The carbonyl values on a per cell basis were even reduced as compared with the NS group. This surprising decrease was not expected, since AMs in BALF of smokers can release twice the amount of $\mathrm{O}_{2}^{-}$compared to those of nonsmokers ex-vivo [11]. The reduced effectiveness of phagocytes in generating protein carbonyl in the lungs of smokers may be due to high cell densities, smoke constituents, or adaptation processes.

In asbestosis, it was proposed that the asbestos fibres may cause chronic release of reactive oxygen metabolites mediating the inflammatory process [33]. An accumulation of protein carbonyl groups was expected due to the iron-containing asbestos fibres, which should favour metal-catalysed oxidation processes. However, we found no difference in BALF protein carbonyl content in ASB-EXS as compared with the NS control. This astonishing result may be explained by the following possibilities: 1) the iron is not released from asbestos and, hence, not available for the site-specific carbonyl formation; 2) asbestos fibres lose their reactivity to initiate oxidative mechanisms with time; or 3) other oxidation processes dominate that do not require iron [33].

Recently, another approach has been reported to study oxidative stress in the lungs by measuring methionine sulphoxide $(\operatorname{Met}(\mathrm{O}))$ formation in BALF proteins [34, 35]. The oxidation of methionine (Met) to $\operatorname{Met}(\mathrm{O})$ requires $\mathrm{H}_{2} \mathrm{O}_{2}$, chloride and MPO activity. This oxidation system produces hypochlorite and chlorinated amines, which are potent oxidants of Met. Significantly increased $\operatorname{Met}(\mathrm{O})$ values were found in IPF-NS patients but not in SARC-NS patients [34] when compared to a NS control. No difference in the $\operatorname{Met}(\mathrm{O})$ response was found between the NS and $\mathrm{S}$ control groups [35]. In contrast to these data, we found increased protein carbonyl values both in, IPF-NS and SARC-NS patients. Major targets of MPO-derived oxidants are Met and thiol sites in proteins and peptides, causing inactivation of proteinase inhibitors [7] and thiol oxidation [36]. On the other hand, metal-catalysed oxidation with hydroxyl radical formation cause lipid peroxidation [37] as well as chain breaks in nucleic acids [38], and damage to proteins [4-6], including collagen [39]. Thus, metal-catalysed oxidation might cause lesions in connective tissue, which is considered to be an early event in the pathogenesis of fibrosing alveolitis. Our results clearly show that the two measures, $\operatorname{Met}(\mathrm{O})$ and protein carbonyl, are complementary and indicate different oxidative mechanisms, which might be responsible for different pathophysiological end-points.

In conclusion, the increase of oxidatively damaged proteins suggests changes in the pulmonary oxidant/antioxidant screen and/or enhanced release of transition metal ions available for metal-catalysed oxidation systems. Proteins that have become dysfunctional by oxidation may play a causal role in the pathogenesis of lung diseases.

\section{References}

1. Freeman BA, Transwell AK. Biochemical and cellular aspects of pulmonary oxygen toxicity. Adv Free Rad Biol Med 1985; 1: 133-164. 
2. Southorn PA, Powis G. Free radicals in medicine. II. Involvement in human disease. Mayo Clin Proc 1988; 63: 390-408.

3. Riley DJ, Kerr JS. Oxidant injury of the extracellular matrix: potential role in the pathogenesis of pulmonary emphysema. Lung 1985; 163: 1-13.

4. Oliver CN. Inactivation of enzymes and oxidative modification of proteins by stimulated neutrophils. Arch Biochem Biophys 1987; 253: 62-72.

5. Stadtman ER. Metal ion-catalysed oxidation of proteins: biochemical mechanism and biological consequences. Free Rad Biol Med 1990; 9: 315-325.

6. Davies KJA. Protein damage and degradation by oxygen radicals. I. General aspects. J Biol Chem 1987; 262: 9895-9901.

7. Carp H, Miller F, Hoidal JR, Janoff A. Potential mechanism of emphysema: $\alpha_{1}$-proteinase inhibitor recovered from lungs of cigarette smokers contains oxidized methionine and has decreased elastase inhibitory capacity. Proc Natl Acad Sci USA 1982; 79: 2041-2045.

8. Maier KL, Matejkova E, Hinze H, Leuschel L, Weber $\mathrm{H}$, Beck-Speier I. Different selectivities of oxidants during oxidation of methionine residues in the $\alpha_{1}$-proteinase inhibitor. FEBS Lett 1989; 250: 221-226.

9. Koren HS, Devlin RB, Graham DE, et al. Ozone-induced inflammation in the lower airways of human subjects. Am Rev Respir Dis 1989; 139: 407-415.

10. Strausz J, Müller-Quernheim J, Steppling H, Ferlinz R. Oxygen radical production by alveolar inflammatory cells in idiopathic pulmonary fibrosis. Am Rev Respir Dis 1990; 141: 124-128.

11. Nakashima H, Ando M, Sugimoto M, Suga M, Soda K, Araki S. Receptor-mediated $\mathrm{O}_{2}^{-}$release by alveolar macrophages and peripheral blood monocytes from smokers and nonsmokers: priming and triggering effects of monomeric IgG, concanavalin A, N-formyl-methionylleucyl-phenylalanine, phorbol myristate acetate, and cytochalasin D. Am Rev Respir Dis 1987; 136: 310-315.

12. Martin RR, Lawrence EC, Teague RB, Gottlieb MC, Putman M. Chemiluminescence of lung macrophages and blood leukocytes in sarcoidosis. Am Rev Respir Dis 1986; 133: 298-301.

13. Fridovich I, Freeman BA. Antioxidant defenses in the lung. Annu Rev Physiol 1986; 48: 693-702.

14. Halliwell B. How to characterize a biological antioxidant. Free Rad Res Commun 1990; 9: 1-32.

15. Maier KL. How the lung deals with oxidants. Eur Respir J 1993; 6: 334-336.

16. Cantin AE, Hubbard RC, Crystal RG. Glutathione deficiency in the epithelial lining fluid of the lower respiratory tract in idiopathic pulmonary fibrosis. Am Rev Respir Dis 1989; 139: 370-372.

17. Cantin AE, North SL, Hubbard RC, Crystal RG. Normal alveolar epithelial lining fluid contains high levels of glutathione. J Appl Physiol 1987; 63: 152-157.

18. Pacht ER, Kaseki H, Mohammed JR, Cornwell DG, Davis WB. Deficiency of vitamin E in the alveolar fluid of cigarette smokers. J Clin Invest 1986; 77: 789-796.

19. Oliver CN, Ahn BW, Moerman EJ, Goldstein S, Stadtman ER. Age-related changes in oxidized proteins. $J$ Biol Chem 1987; 262: 5488-5491.

20. Starke-Reed PE, Oliver CN. Protein oxidation and proteolysis during aging and oxidative stress. Arch Biochem Biophys 1989; 275: 559-567.
21. Lenz A-G, Costabel U, Shaltiel S, Levine RL. Determination of carbonyl groups in oxidatively modified proteins. Anal Biochem 1988; 177: 419-425.

22. Levine RL, Garland D, Oliver CN, et al. Determination of carbonyl groups in oxidatively modified protein. In: Packer L, Glazer AN, eds. New York, Academic press. Methods Enzymol 1990; 186: 464-478.

23. Stadtman ER. Oxidation of free amino acids and amino acid residues in proteins by radiolysis and by metalcatalysed reactions. Annu Rev Biochem 1993; 62: 797821.

24. Halliwell B, Gutteridge JMC. Oxygen toxicity, oxygen radicals, transition metals and disease. Biochem J 1984; 219: 1-14.

25. Thompson AB, Bohling T, Heires A, Linder J, Rennard SI. Lower respiratory tract iron burden is increased in association with cigarette smoking. J Lab Clin Med 1991; 117: 493-499.

26. Lenz A-G, Krombach F, Maier KL. Oxidative stress in vivo and in vitro: modulation by quartz dust and hyperbaric atmosphere. Free Rad Biol Med 1992; 12: 1-10.

27. Gladstone IM, Levine RL. Oxidation of proteins in neonatal lungs. Pediatrics 1994; 93: 764-768.

28. Costabel U, Bross KJ, Mattys H. The immunoperoxidase slide assay: a new method for the demonstration of surface antigens on bronchoalveolar lavage cells. Bull Eur Physiopathol Respir 1985; 21: 381-387.

29. Stadtman ER. Protein oxidation and aging. Science 1992; 257: 1220-1224.

30. Vandenplas O, Depelchin S, Delaunois L, Delwiche J$\mathrm{P}$, Sibille Y. Bronchoalveolar lavage immunoglobulin $\mathrm{A}$ and $\mathrm{G}$ and antiproteases correlate with changes in diffusion indices during the natural course of pulmonary sarcoidosis. Eur Respir J 1994; 7: 1856-1864.

31. Pacifici R, Davies KJA. Protein degradation as an index of oxidative stress. In: Packer L, Glazer AN, eds. New York, Academic press. Methods Enzymol 1990; 186: 485-502.

32. Stadtman ER. Covalent modification reactions are marking steps in protein turnover. Biochem 1990; 29: 6323-6331.

33. Kamp DW, Graceffa P, Pryor WA, Weitzman SA. The role of free radicals in asbestos-induced diseases. Free Rad Biol Med 1992; 12: 293-315.

34. Maier K, Leuschel L, Costabel U. Increased levels of oxidized methionine residues in bronchoalveolar lavage fluid proteins from patients with idiopathic pulmonary fibrosis. Am Rev Respir Dis 1991; 143: 271-274.

35. Maier KL, Leuschel L, Costabel U. Increased oxidized methionine residues in BAL fluid proteins in acute or chronic bronchitis. Eur Respir J 1992; 5: 651-658.

36. Aruoma OI, Halliwell B, Hoey BM, Butler J. The antioxidant action of $\mathrm{N}$-acetylcysteine: its reaction with hydrogen peroxide, hydroxyl radical, superoxide and hypochlorous acid. Free Rad Biol Med. 1989; 6: 593-597.

37. Halliwell B, Gutteridge JMC. Lipid peroxidation, oxygen radicals, cell damage and antioxidant therapy. Lancet 1984; 1: 1396-1398.

38. Halliwell B, Aruoma OI. DNA damage by oxygenderived species: its mechanism and measurement in mammalian systems. FEBS Lett 1991; 281: 9-19.

39. Curran SF, Amoruso MA, Goldstein BD, Berg RA. Degradation of soluble collagen by ozone or hydroxyl radicals. FEBS Lett 1984; 176: 155-160. 